(2) Open Access Full Text Article

\title{
Investigation of the Role of Glucose Decorated Chitosan and PLGA Nanoparticles as Blocking Agents to Glucose Transporters of Tumor Cells
}

This article was published in the following Dove Press journal: International Journal of Nanomedicine

\author{
Ahmad Abolhasani' \\ Davoud Biria (D) \\ Hoda Abolhasani ${ }^{2}$ \\ Ali Zarrabi (D) ${ }^{\prime}$ \\ Tahereh Komeili $\mathbb{D D}^{2}$ \\ 'Department of Biotechnology, \\ University of Isfahan, Isfahan, Iran; \\ ${ }^{2}$ Department of Physiology and \\ Pharmacology, Qom University of \\ Medical Sciences, Qom, Iran
}

Purpose: Glucose decorated PLGA and chitosan nanoparticles (GPNPs and GCNPs) have been developed to examine the possibility of preventing the facilitated glucose transport to the cells through blocking the glucose transporters (Gluts) overexpressed by tumor cells.

Methods: The MTT assay was used to assess the cytotoxicity towards human colon tumor (HT-29) cells in 72 hrs. Fluorescence microscopy was employed to confirm the attachment of GPNPs to the cells. Moreover, the GPNPs effects on the apoptotic rate of HT-29 cells were analyzed. Finally, the expression levels of GLUT-1 and GLUT-4 by real-time polymerase chain reaction (RT-PCR) were assayed to investigate the response of HT-29 cells to blocking their Gluts by GPNPs.

Results: The stability studies showed that the synthesized complexes were mostly stable (more than $80 \%$ ) at various temperatures $\left(4\right.$ to $\left.40^{\circ} \mathrm{C}\right)$ and $\mathrm{pH}(5.4$ to 7.4$)$ conditions. Results indicated that the survival rate of the cells was decreased to $43 \%$ and $46 \%$ after treatment with GCNPs and GPNPs, respectively. Also, the apoptosis assay results showed that the percentage of viable cells reduced to $47 \%$ after GPNPs treatment. These observations were justified by the specific interactions between the glucose terminals and the cells Gluts which resulted in blocking the entries of nutrients to the cells. It was revealed that the GLUT-1 mRNA expression after the first $24 \mathrm{~h}$ of treatment by GPNPs was upregulated to more than $145 \%$, while the direction was reversed after $72 \mathrm{~h}$ (expression less than $45 \%$ ), which coincided with the cells death. In the first $24 \mathrm{~h}$, the glucose deprivation stimulated the expression of Glut-1 while the apoptotic enzymes expression was dominant at the end of $72 \mathrm{~h}$ treatment time.

Conclusion: Finally, it can be concluded that the glucose-nanoparticle complexes could be considered as promising agents in cancer therapy.

Keywords: glucose decorated nanoparticles, PLGA, chitosan, glut, tumor cells

\section{Introduction}

Targeted drug delivery systems are of high interest in cancer treatment because of their remarkable advantages over their free counterparts, such as active drug protection, lower toxicity, and increased retention and permeation in cancerous tissues. ${ }^{1-4}$ Membrane-bound tumor-associated proteins are often considered as the cellular targets to enhance the smart delivery capabilities of the drug system. ${ }^{5}$ The glucose transporter protein group named Glut as membrane-embedded proteins impress the intracellular glucose transport to supply the cellular activities energy. ${ }^{6}$ In the $1927 \mathrm{~s}$
Correspondence: Davoud Biria

Department of Biotechnology, University of Isfahan, P.O. Box: 8I7467344I, Isfahan, Iran

Tel +983137934373

Email d.biria@ast.ui.ac.ir 
for the first time, Warburg reported that the uptake and metabolism of glucose in carcinomatous cells were more intensive than the healthy cells. ${ }^{7}$ Subsequently, further works showed that Gluts could be considered as the markers for primary carcinoma detection and prognoses. ${ }^{8,9}$ As a result, for applications in specific therapies, several glucose conjugated prodrugs have been evaluated. For instance, in 2007, Liu investigated the glucose loaded paclitaxel targeting effects on cancerous cells. ${ }^{10}$ They showed that the addition of methyl glucoside enhanced the solubility, stability, and pharmaceutical properties of paclitaxel. Moreover, the specific targeting delivery of the drug to human breast cancer cells (MCF-7) was improved. Cancer cells would quickly internalize the ligand upon binding of glucose to a Glut through forming the receptor-ligand complex. Afterward, the receptor is recycled to the cell surface to be in service for subsequent glucose transportation. This interaction has been considered as the core of effective drug delivery systems through the application of Gluts as the tumor-specific targets. ${ }^{11,12}$ Accordingly, glucose-decorated nanoparticles have been considered as potentially attractive tumor-targeted drug vehicles. For example, due to the facilitative Glut overexpression on glioma cells and blood-brain barrier (BBB), Jiang X designed poly(ethylene glycol)-copoly(trimethylene carbonate) nanoparticles conjugated with 2-deoxy-d-glucose as a potential system for dual-targeted drug delivery that increasing the $\mathrm{BBB}$ permeation and improving the drug accumulation in the glioma via Glutmediated transcytosis and Glut-mediated endocytosis, respectively. ${ }^{13}$ In another study, 2-amino-2-deoxyglucose modified cobalt ferrite magnetic nanoparticles were developed for targeting of MCF-7 cells, as a potential agent for targeted drug/gene delivery. ${ }^{14}$ GCNPs had also been employed for targeted drug delivery to enhance doxorubicin transfer efficiency in 4T1 tumor cells. The GCNPs showed better endocytosis ability than CNPs during the in vitro studies of cellular uptake, and the anti-tumor activity of doxorubicin/GCNPs was 4-5 times more than doxorubicin/CNPs in killing 4T1 cells. ${ }^{15}$

On the other hand, glucose-decorated nanoparticles can be applied as the blocking agents to the channels of membrane-embedded proteins on the tumor cells by irreversible reaction with the glucose receptors. The valid binding of glucose to the proper nanoparticles can form a stable complex with a high affinity to the Gluts of the tumor cells. However, the uptake of the glucose-nanoparticle complex into the cells will be hindered by the spatial disturbance of the nanoparticle, leading to the inactivation of the receptor and finally, to the death of cells. The utilized nanoparticles should possess active functional groups to form stable bonds with glucose and simultaneously have proper characteristics, including biocompatibility and non-toxicity, for application in a drug system. Nevertheless, the feasibility and effectiveness of the proposed mechanism must be thoroughly examined.

Among the nanoparticulate carriers, chitosan and poly (lactic-co-glycolic acid) (PLGA) nanoparticles (CNPs and PNPs) have tremendous potential in the applications combining targeting, imaging, diagnostics, and therapy. Conjugation or encapsulation of agents in chitosan and PLGA nanocarriers reduces the undesirable shortcomings of the therapeutic agents, such as short circulation half-life and non-site-specific targeting. Chitosan is a cationic biopolymer extensively studied as a pharmaceutical biomaterial because of its essential features such as biodegradability, biocompatibility, nontoxicity, and low immunogenicity. ${ }^{16,17}$ CNPs have widely been investigated for their potential applications as drug delivery systems. ${ }^{18,19}$ Furthermore, PLGA is a synthetic polymer, which has received considerable interest because of its biocompatibility and biodegradability. PLGA has been verified for parenteral administration by the Food and Drug Administration (FDA) and the European Medical Agency (EMA) in drug delivery systems. PNPs have been successfully applied for passive targeting of the tumor via the enhanced permeability and retention (EPR) effect as well as active targeting by modification of their surface with tumorspecific ligands. PNPs with a targeting moiety have been vastly investigated in preclinical researches. ${ }^{20,21}$

Based on the above, an active targeted drug delivery system, which consists of a complex of glucose with CNPs or PNPs, has been presented in this work. The stability of the prepared complexes was first examined in various conditions. The interactions of the complex with the tumor cell membranes were then studied to confirm the effectiveness of the proposed mechanism of blocking the nutrient entries to the cells. The anti-cancer activities of the designed complexes were considered in vitro and compared to cisplatin as a commercial drug. The GPNPs treatment capability to apoptosis induction in HT-29 cells was investigated to found the relationship between anti-proliferation and apoptosis. Moreover, the expression pattern of main glucose transporter proteins in HT-29 cells before and after treatment with PNPs and GPNPs was analyzed to find the molecular mechanism by which GPNPs induce apoptosis. 


\section{Experimentals}

\section{Materials}

Poly(lactic-co-glycolic acid) (PLGA) nanoparticles (100 nm average diameter), low molecular weight chitosan derived from crab shell (water-soluble, viscosity $35 \mathrm{cps}$, deacetylation degree $91.5 \%$ ), sodium tripolyphosphate (TPP), sodium methoxide-methanol, succinic anhydride, triethylamine, 1-ethyl-3-(3-dimethyl aminopropyl)carbodiimide (EDC), N-hydroxysuccinimide (NHS), fluorescein isothiocyanate (FITC), dichloromethane, 3-(4,5-dimethylthiazol-2-yl)-2,5diphenyl tetrazolium bromide (MTT) and dimethyl sulfoxide (DMSO), were obtained from Sigma Aldrich Chemical Co (USA). Roswell Park Memorial Institute medium (RPMI 1640), fetal bovine serum (FBS), and cisplatin were bought from INOCLON (Iran), Gibco (USA), and MYLAN (USA), respectively. Glucosamine, glacial acetic acid, and sodium hydroxide and all other chemicals were supplied by Merck Chemical Co (Germany). Ultrapure water was used in all the experiments. CNPs were synthesized by the modified method of Calvo. ${ }^{22}$ Glucose conjugated nanoparticles were prepared according to the procedure reported by Chen for the preparation of glucose CNPs (Figure 1s, Supplementary materials). ${ }^{23}$ PLGA nanoparticles were conjugated with glucose via the carbodiimide coupling reaction (Figure 2s, Supplementary materials). The extended explanations for CNPs synthesis, characterization of nanoparticles (Figure $3 \mathrm{~s}$ and $\underline{4 \mathrm{~s}}$ ), and their glucose conjugation (Figures $5 \mathrm{~s}, \underline{6 \mathrm{~s}}$, and $\underline{7 \mathrm{~s}}$ ) have been described in detail in the Supplementary materials.

\section{Cell Culture}

HT-29 cell line was supplied from the Pasteur Institute (Tehran, Iran). HT-29 cell lines are well known as powerful tools in studying colon cancer resistance to chemotherapy since they are capable of mirroring the heterogeneity of tumor cells in vivo. ${ }^{24}$ These particular cells have been extensively applied in the screening of potential anti-tumor compounds. The cells were used within two weeks after removing from liquid nitrogen storage. All cell lines were cultured in RPMI 1640 medium completed with $10 \%(\mathrm{v} / \mathrm{v})$ FBS, penicillin G-streptomycin (100 U/mL and $100 \mu \mathrm{g} / \mathrm{mL})$ and L-glutamine $(2 \mathrm{mM})$ in an incubator with the humidified atmosphere at $37^{\circ} \mathrm{C}$, which contained $5 \% \mathrm{CO}_{2}$. The obtained cultures with the confluency of over $90 \%$ were utilized in the experiments.

\section{Stability Study}

The stability study was performed using both the synthesized glucose nanoparticle complexes (GCNPs and GPNPs) ${ }^{25}$ Phosphate buffer saline (PBS) solution $(0.2$ $\mathrm{mol} / \mathrm{L}$ and $\mathrm{pH}=7.4$ ) was used to suspend the complexes in the aqueous phase. First, the $\mathrm{pH}$ values of the solutions were adjusted to the desired values $(5.4,6.4,7.4)$ by adding $\mathrm{HCl}(0.1 \mathrm{~N})$ to the tubes. Next, each complex was divided into nine sample sets, suspended in separate tubes containing equal volumes of the solution and stored in three various temperatures (i.e., in a refrigerator $\left(\mathrm{T}=4^{\circ}\right.$ C), ambient temperature $\left(\mathrm{T}=25^{\circ} \mathrm{C}\right)$ and $40^{\circ} \mathrm{C}$ and $75 \% \mathrm{RH}$ in a humidity-controlled oven). The free glucose content of all samples was determined during 24 days (after 1, 2, $3,4,6,8,10,12$, and 24 days) as described below.

The initial glucose nanoparticle complex content of the mixtures was adjusted to obtain a maximum glucose concentration of $1 \mathrm{mg} / \mathrm{mL}$ concerning the calculated DS values (DS calculations have been explained in the Supplementary materials). The nanoparticles were harvested from the mixture by centrifugation at $18,000 \mathrm{rpm}$ for $40 \mathrm{~min}$ at $25^{\circ} \mathrm{C}$. The percentage of the released glucose in the obtained supernatant was determined at different time intervals through equation (1) using a UV-visible spectrophotometer at $520 \mathrm{~nm}$ after proper dilution. All measurements were carried out in triplicates.

$$
\begin{aligned}
\% \text { Released glucose }= & (\text { Released glucose absorption }) \\
& /(\text { Total amount of glucose absorption }) * 100
\end{aligned}
$$

\section{Cytotoxicity Assay}

The anti-proliferative activity of the synthesized complexes against HT-29 cells was evaluated by MTT assay. ${ }^{26,27}$ Various concentrations $(0.001,0.01,0.1,1,10$, and $100 \mu \mathrm{M})$ of the synthesized nanoparticulate complexes and an anti-cancer drug (cisplatin) were used along the cell line HT-29. Trypan blue staining was employed to determine the cell count and viability, followed by enumeration by a hemocytometer. All cells were seeded at the density of 7000 cells per well of 96-well plates in a $200 \mu \mathrm{L}$ medium (RPMI 1640) and allowed to attach overnight (pre-incubation). After $12 \mathrm{~h}$, upon the formation of a partial cell monolayer, the supernatant content of the wells was replaced with $200 \mu \mathrm{L}$ of medium containing desired concentrations of the anti-cancer drug or the synthesized complexes. The confluence of the cells was about $40-50 \%$ at the time of exposure. It should be noted 
that a medium containing $1 \mathrm{mM}$ hydrogen peroxide was utilized as the positive control to determine the cells minimal viability (MinV) and the negative control was considered thorough inspection of the intact cells exposed to a medium without any drug or synthesized complexes to obtain the maximum viability (MaxV). Afterward, all the plates were incubated at $37^{\circ} \mathrm{C}$ for $72 \mathrm{~h}$ in a humidified incubator with $5 \% \mathrm{CO}_{2}$. MTT solution was first provided as a $5 \mathrm{mg} / \mathrm{mL}$ stock solution in PBS $(\mathrm{pH}=7.2)$ and filtered by a $0.22 \mu \mathrm{m}$ BIOFIL syringe filter. Following the $72 \mathrm{~h}$ incubation period, the solutions in the wells were discarded and $200 \mu \mathrm{L}$ of the prepared MTT solution was added to each well. The plates were incubated for $4 \mathrm{hrs}$ at $37^{\circ} \mathrm{C}$ under a $5 \% \mathrm{CO}_{2}$ atmosphere. A dark blue formazan product is produced by viable cells, while the dead cells form no such staining. Subsequently, the supernatant was removed by flipping the plates and tapping gently on a paper towel. Then, $200 \mu \mathrm{L}$ of DMSO and $25 \mu \mathrm{l}$ of Sorensenś glycine buffer $(0.1 \quad \mathrm{M}$ glycine plus $0.1 \mathrm{M} \mathrm{NaCl}$ equilibrated at $\mathrm{pH} 10.5$ using $0.1 \mathrm{M} \mathrm{NaOH}$ ) was added to each well as the stopper, and the plates were shaken on a plate shaker for $40 \mathrm{~min}$. Finally, an enzymelinked immunosorbent assay (ELISA) reader was employed at $570 \mathrm{~nm}$ to measure the optical density values of the 96-well plates to calculate the cell viability. The assay was carried out in triplicate for all the samples. The growth inhibition percentage was calculated using equation (2). Also, a dose-response analysis was performed to calculate $\mathrm{IC}_{50}$ values (concentration of drugs required for $50 \%$ cell growth inhibition) from curves by fitting the obtained data to a sigmoidal model through nonlinear regression analysis using GraphPad PRISM software (version2.01, GraghPad Software, Inc. USA).

$$
\% \text { Growth Inhibition }=1-\left[\begin{array}{l}
(\text { test }-M i n V) / \\
(\operatorname{MaxV}-M i n V)
\end{array}\right] * 100
$$

The $\mathrm{pH}$ variations of cell culture media were also monitored to determine whether the cells have entered the anaerobic mode of metabolism because of their nutrients entries blockage by the glucose-nanoparticle complexes.

\section{Preparation of FITC Conjugated PNPs and GPNPs}

Since the purchased PNPs, with an average diameter of 100 $\mathrm{nm}$ were smaller in mean particle size than the synthesized CNPs and had a narrower particle size distribution, we preferred PNPs to CNPs for the next experiments. FITCPNPs and FITC-GPNPs were obtained by covalent conjugation of FITC to the EDC activated carboxylic terminal groups of PLGA polymers via modified carbodiimide method. $^{28,29} 10 \mathrm{mg}$ of PNPs (or GPNPs) were dissolved in $1 \mathrm{~mL}$ of dichloromethane and activated using $8 \mathrm{mg}$ of NHS and $10 \mathrm{mg}$ of EDC. The reaction mixture was incubated with constant end-over-end rotation using a Revolver TM rotator (Labnet International, Inc. Woodbridge, NJ, USA) for $2 \mathrm{hrs}$ at ambient temperature. $3.9 \mathrm{mg}$ of FITC $(10 \mu \mathrm{l})$ was then dissolved in a mixture of $50 \mu$ of dichloromethane (DCM) and $50 \mu \mathrm{l}$ of pyridine. Subsequently, the FITC solution was added to the activated PLGA solution at a molar ratio of $1: 1$, and the reaction mixture was incubated in the dark overnight at $4{ }^{\circ} \mathrm{C}$. Repeated washings using $5 \mathrm{mM} \mathrm{HCl}$ removed the unreacted FITC until the aqueous layer remained clear and then, nanoparticles precipitated with $22 \mathrm{~mL}$ methanol for $2 \mathrm{hrs}$ at $4^{\circ} \mathrm{C}$. The nanoparticles were centrifuged at $15,000 \mathrm{~g}$ for $30 \mathrm{~min}$. The supernatant was discarded, and the nanoparticles were washed entirely with Milli-Q water and lyophilized. FITC conjugated nanoparticle samples for cellular uptake were obtained by blending pure and FITC-labeled one at a 50/50 weight ratio. The lyophilized FITC-PNPs and FITC-GPNPs were kept in the dark at $4{ }^{\circ} \mathrm{C} .{ }^{1} \mathrm{H}$ nuclear magnetic resonance $\left({ }^{1} \mathrm{H}\right.$ NMR) spectra, recorded on a Bruker $500 \mathrm{MHz}{ }^{1} \mathrm{H}$ NMR spectrometer (Bruker, Germany) in $\mathrm{CDCl}_{3}$ at $25^{\circ} \mathrm{C}$ were used to analyze the chemical structures of the intact PNPs as well as those conjugated with FITC (Figure 8s, Supplementary materials).

\section{Cellular Uptake of FITC Conjugated GPNPs}

HT-29 cells were incubated with FITC-PNPs and FITCGPNPs for $24 \mathrm{~h}$ to evaluate the specific interactions between glucose loaded nanoparticles and Gluts overexpressed in cancerous cells. Clearly, the bare FITC-PNPs (with no glucose ligands) were used as the negative control in the experiments. The culturing and preparation of HT-29 cells were carried out, as explained in section 2.2. All cells were seeded at the density of $5 \times 10^{4}$ cells per well of 12-well plates in a 900-1000 $\mu \mathrm{L}$ medium and allowed to attach overnight (pre-incubation). The supernatant was removed, and $900-1000 \mu \mathrm{L}$ of a medium containing 100 $\mu \mathrm{M}$ FITC-PNPs or FITC-GPNPs were added to the wells in the 12-well plates. The compound solutions in the wells were discarded after $24 \mathrm{~h}$ exposure of FITC-PNPs or FITC-GPNPs. Subsequently, all the plates were incubated at $37^{\circ} \mathrm{C}$ for $24 \mathrm{~h}$ in a humidified incubator with $5 \% \mathrm{CO}_{2}$. 
Then the cells were washed two times with PBS and observed through a fluorescence microscope (DMI6000B, Leica, Germany) with a UV filter (excitation filter: D350, emission filter: D460/50 m).

\section{Apoptosis Assay by Annexin V-FITC/PI Flow Cytometer}

The apoptotic status of HT-29 cells was assessed by evaluating the phosphatidylserine exposure on the cell membranes through the application of Annexin V-fluorescein isothiocyanate (Annexin V-FITC) and propidium iodide (PI) staining. ${ }^{30}$ The Annexin V-FITC tests were performed by the Annexin V-FITC assay kit (MabTag GmbH), following the protocols provided. HT-29 cells incubated in RPMI 1640 culture medium (1\% double-antibody, 10\% FBS) were adjusted to a cell concentration of $7.5 \times 10^{4}$ cell $/ \mathrm{mL}$. The cell suspension was added to the 6 -well cell culture microplates $(4 \mathrm{~mL} / w e l l)$. The microplates were then put into an incubator containing $5 \% \mathrm{CO}_{2}$ at $37^{\circ} \mathrm{C}$ for 48 h. Afterward, the cells were subjected to four treatments: (1) RPMI, (2) PNPs, (3) GPNPs, and (4) cisplatin at $\mathrm{IC}_{50}$ concentrations of $2.54 \mu \mathrm{M}$ for cisplatin and $85.01 \mu \mathrm{M}$ for GPNPs and PNPs and incubated under the same conditions for $72 \mathrm{~h}$. The RPMI treatment was the control negative.

Next, the cells were detached by trypsin and centrifuged at $400 \mathrm{~g}$ for $15 \mathrm{~min}$. After washing three times with PBS, the cells were suspended in a solution containing $5 \mu \mathrm{L}$ of Annexin V-FITC and $195 \mu \mathrm{L}$ of the diluted cell suspension binding buffer. The diluted binding buffer prepared by adding $50 \mathrm{~mL}$ of the stock binding buffer (10 mM HEPES/NaOH pH 7.4; $140 \mathrm{mM} \mathrm{NaCl}, 2.5 \mathrm{mM}$ $\mathrm{CaCl}_{2}$ ) to $150 \mathrm{~mL}$ distilled water. The cell suspension was well mixed and incubated for less than 15 min in dark ambient. Then, the cells were washed and re-suspended in the binding buffer $(190 \mu \mathrm{L})$, and finally, the PI solution (prepare fresh as required by $10 \times$ dilution of PI stock in Annexin V Binding Buffer) was added $(10 \mu \mathrm{L})$. Flow cytometry analysis (Attune NxT, Life technologies, Singapore) was carried out after keeping the cells on ice. The assay was performed in triplicate for each sample.

\section{Real-Time Polymerase Chain Reaction Analysis (RT-PCR)}

Six-well culture plates containing HT- 29 cells $\left(3 \times 10^{5}\right.$ cell/ well) treated by PNPs and GPNPs $\left(\mathrm{IC}_{50}=85.01 \mu \mathrm{M}\right)$ were incubated at $37^{\circ} \mathrm{C}$ for $72 \mathrm{~h}$ in a humidified incubator with $5 \%$ $\mathrm{CO}_{2}$. Afterward, based on the manufacturer's protocol of RNA extraction (SinaPure KIT, SINACLON, Iran), the cells were lysed, and their total RNA was extracted. The isolated RNA concentration and purity were measured by a nanodrop spectrophotometer (NanoDrop One; Thermo Fisher Scientific, USA) and to ensure that the isolated RNA was reasonably pure, an optical density 260/280 ratio between 1.8 and 2.0 was deemed. RNA samples were stored at $-20^{\circ} \mathrm{C}$. Reverse transcription was performed for RT-PCR by the following procedure (2-steps RT-PCR Kit; Vivantis Technologies, Malaysia). Briefly, the RNA-primer mixture was first prepared as follows: $5 \mu \mathrm{g}$ of total RNA was contained in a ten $\mu$ reaction volume with $1 \mu \mathrm{L}$ of oligo $\mathrm{d}(\mathrm{T})$ primer solution $(40 \mu \mathrm{M}), 1 \mu \mathrm{L}$ of dNTP mixture $(10 \mathrm{mM})$ and nuclease-free water top up to 10 $\mu \mathrm{L}$. The reaction mixture was then incubated and predenatured at $65{ }^{\circ} \mathrm{C}$ for $5 \mathrm{~min}$, chilled on ice for $2 \mathrm{~min}$ and briefly spun down. After preparation of cDNA, ten $\mu \mathrm{L}$ of a synthesis mixture containing $2 \mu \mathrm{L}$ of $10 \mathrm{X}$ Moloney murine leukemia virus (MMLV) buffer, $100 \mathrm{U}$ of MMLV reverse transcriptase and nuclease-free water top up to $10 \mu \mathrm{L}$ was added into each RNA-primer mixture, then mixed gently and centrifuged. Afterward, the samples were incubated at $42^{\circ} \mathrm{C}$ for about $1 \mathrm{hr}$ and eventually annealed at $85^{\circ} \mathrm{C}$ for $5 \mathrm{~min}$ to terminate the reaction. The synthesized cDNA can be directly used for downstream applications or stored at $-20^{\circ} \mathrm{C}$. The synthesized cDNAs were used as templates for RT-PCR using the fluorescent dye SYBR Green and the StepOnePlus RT-PCR system (Applied Biosystems; Thermo Fisher Scientific, Singapore). The $20 \mu \mathrm{L}$ reaction mixture included $10 \mu \mathrm{L}$ of $2 \times$ SYBR Green buffer, $1 \mu \mathrm{L}$ of the template, $1 \mu \mathrm{L}$ of upstream and downstream specific primers, and $8 \mu \mathrm{L}$ of deionized water. RT-PCR included initial denaturing for $10 \mathrm{~min}$ at $95^{\circ} \mathrm{C}, 40$ cycles at $95^{\circ} \mathrm{C}$ for $15 \mathrm{~s}, 59^{\circ} \mathrm{C}$ for $20 \mathrm{~s}$, and $72^{\circ} \mathrm{C}$ for $20 \mathrm{~s}$. The primers used were as follows: GLUT-1 Forward (F): 5'-TCAACACGGCCTTCACTG-3'; GLUT-1 Reverse (R): 5'CACGATGCTCAGATAGGACA-3'; GLUT-4 Forward (F): 5'-CGGTTCTTTCATCTTCGCCG-3' and GLUT-4 Reverse (R): 5'-TTCCCCATCTTCGGAGCCTA- 3'. Each sample was assayed in triplicate, and the cycle threshold (CT) values were normalized to $\beta$-actin (ACT $\beta$ Forward (F): $5^{\prime}$-AGGT CTTTGCGGATGTCCACGT-3'; ACT $\beta$ Reverse (R): 5'-CAC CATTGGCAATGAGCGGTTC-3'). ${ }^{31,32}$

\section{Statistical Analysis}

All the data were represented as a mean plus the standard deviations (SD) of the triplicate, in this study. Statistical analyses were conducted using SPSS software system. The significance of the difference between control and treated 
groups was performed using one-way ANOVA, and $P$ values of $<0.05$ were considered statistically significant.

\section{Results}

\section{Stability Study}

The results of stability tests for GCNPs and GPNPs complexes after 24 days under different storage conditions have been shown in Table 1. The calculated glucose release percentages of the entire incubation period (after 1, 2, 3, 4, 6, 8, 10, 12 , and 24 days) have been shown in Figure 9s (Supplementary materials). It was demonstrated that there was a significant increase in the released glucose content after 24 days when the storage temperature increased from $4^{\circ}$ $\mathrm{C}$ to $40{ }^{\circ} \mathrm{C}(\mathrm{P}<0.05)$. Higher temperatures are believed to accelerate complex degradation, which in turn will increase the glucose release. Moreover, the release of glucose was lower in acidic conditions than the higher $\mathrm{pH}$ values $(\mathrm{P}<0.05)$. The maximum glucose release after 24 days from GCNPs and GPNPs at $\mathrm{pH}=5.4$ and $40{ }^{\circ} \mathrm{C}$ was $9.9 \%$ and $8.3 \%$, respectively, while at $\mathrm{pH}=7.4$ and the same temperature, $19.9 \%$ and $13.3 \%$ of the glucose was released from the mentioned formulizations after 24 days. However, the amounts of the attached glucose to the nanoparticles were more than $80 \%$, which confirmed the stability of the utilized complexes.

\section{Cytotoxicity Evaluation of Glucose-Nanoparticles Complexes}

The impacts of GCNPs, GPNPs, and Cisplatin (an anti-cancer drug) on the viability of the HT-29 cells have been investigated for a period of $72 \mathrm{~h}$ by the MTT assay, and the obtained results have been summarized in Table 2. A dose-dependent

Table I Glucose Release Percentages of the Complexes Treated in Various $\mathrm{pH}$ and Temperature Conditions After 24 Days (Stability Tests)

\begin{tabular}{|l|l|l|}
\hline Treatment Conditions & $\begin{array}{l}\text { GPNPs } \\
\text { Glucose } \\
\text { Release \% }\end{array}$ & $\begin{array}{l}\text { GCNPs } \\
\text { Glucose } \\
\text { Release \% }\end{array}$ \\
\hline $\mathrm{pH}=5.4, \mathrm{~T}=4^{\circ} \mathrm{C}$ & $2.8 \pm 0.1$ & $3.2 \pm 0.1$ \\
$\mathrm{pH}=5.4, \mathrm{~T}=25^{\circ} \mathrm{C}$ & $4.6 \pm 0.2$ & $7.2 \pm 0.4$ \\
$\mathrm{pH}=5.4, \mathrm{~T}=40^{\circ} \mathrm{C} / 75 \% \mathrm{RH}$ & $8.3 \pm 0.5$ & $9.9 \pm 1.0$ \\
$\mathrm{pH}=6.4, \mathrm{~T}=4^{\circ} \mathrm{C}$ & $4.4 \pm 0.3$ & $4.8 \pm 0.4$ \\
$\mathrm{pH}=6.4, \mathrm{~T}=25^{\circ} \mathrm{C}$ & $7.4 \pm 0.8$ & $8.2 \pm 1.1$ \\
$\mathrm{pH}=6.4, \mathrm{~T}=40^{\circ} \mathrm{C} / 75 \% \mathrm{RH}$ & $\mathrm{II} .3 \pm 1.2$ & $\mathrm{II} .9 \pm 1.6$ \\
$\mathrm{pH}=7.4, \mathrm{~T}=4^{\circ} \mathrm{C}$ & $5.4 \pm 0.5$ & $5.6 \pm 0.6$ \\
$\mathrm{pH}=7.4, \mathrm{~T}=25^{\circ} \mathrm{C}$ & $8.6 \pm 0.9$ & $\mathrm{II} .2 \pm 1.3$ \\
$\mathrm{pH}=7.4, \mathrm{~T}=40^{\circ} \mathrm{C} / 75 \% \mathrm{RH}$ & $13.3 \pm \mathrm{I} .7$ & $19.9 \pm 2.2$ \\
\hline
\end{tabular}

Note: ${ }^{\text {a }}$ ata are presented as Mean \pm SD for triplicates.
Table 2 The Calculated $I C_{50}$ Values for Various Compounds After $72 \mathrm{H}$ by Fitting the Obtained Data to the Sigmoidal DoseResponse Curve

\begin{tabular}{|l|l|l|}
\hline Compound & $\begin{array}{l}\text { HT-29 } \text { IC }_{\mathbf{5 0}} \pm \text { RSD }^{\mathbf{a}} \\
(\boldsymbol{\mu M})\end{array}$ & $\begin{array}{l}\text { \% Cell Viability (at I00 } \\
\boldsymbol{\mu M})\end{array}$ \\
\hline Cisplatin & $2.54 \pm 0.51$ & 97.8 \\
GCNPs & $70.31 \pm 0.10$ & 57.3 \\
GPNPs & $85.01 \pm 0.10$ & 54 \\
\hline
\end{tabular}

Note: ${ }^{a}$ Data are presented as Mean \pm SD for triplicates.

profile was derived for the cytotoxicity of both GCNPs and GPNPs to HT-29 cells, which represented the cell viability for GCNPs and GPNPs against HT-29 cells (Figure 1). The cell viability assay resulted in $57 \%$ and $54 \%$ reduction $(\mathrm{P}<0.05)$ in the cells' survival after $72 \mathrm{~h}$ of incubation for GCNPs and GPNPs, respectively. GCNPs and GPNPs clearly showed a potent anti-proliferative activity on HT-29 cells after 72 $\mathrm{h}$ with the obtained $\mathrm{IC}_{50}$ values of 70.312 and $85.014 \mu \mathrm{M}$ which also were much higher than that of the positive control (Cisplatin with $\mathrm{IC}_{50}$ of $2.541 \mu \mathrm{M}$ ). However, it should be noted that the examined glucose nanoparticle complex in this study contains no specific anti-cancer drugs.

In the case of PNPs, cytotoxicity towards the HT-29 cell line was not shown by the samples during the test period, whereas CNPs had remarkable anti-proliferative activity. This can be explained by the fact that chitosan is far more soluble in acidic media. Thus, the precipitation of CNPs solution (with acetic acid as a solvent) takes place upon its addition to the aqueous medium. CNPs can considerably adhere to the cell surfaces in just $30 \mathrm{~min}$, and for this reason, CNPs show antibacterial activity. The antibacterial activity of CNPs has been reported to be significantly higher than that of chitosan due to the effect of size.

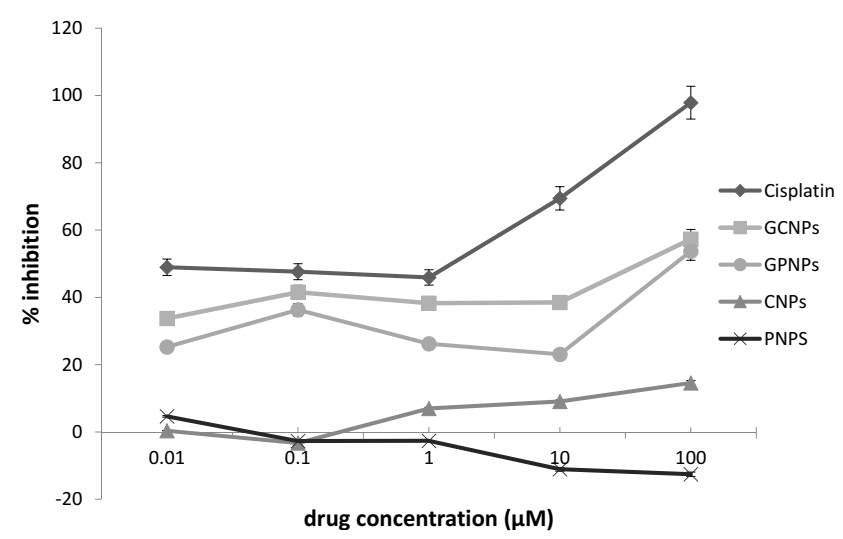

Figure I Dose-response curves for cisplatin (an anti-cancer drug), GCNPs, GPNPs, CNPs and PNPs in $72 \mathrm{~h}$. 
The $\mathrm{pH}$ variations of the media during the cytotoxicity tests have been shown in Figure 2. As can be seen, when the cells were incubated with the various concentrations of the nanoparticle complexes for a period of $72 \mathrm{~h}$, the cells anaerobic mode of metabolism has been intensified resulting in a more acidic condition. This occurs mainly because of the blocking of the cells entries for nutrients by the glucose-nanoparticle complexes, which gradually decreases the $\mathrm{pH}$ over time. In contrast, no significant changes were detected in the $\mathrm{pH}$ of the cell culture media treated with RPMI (Figure 2).

\section{Cellular Uptake of FITC Conjugated GPNPs}

1 HNMR spectroscopy was used to confirm binding of FITC to PNPs, and the obtained spectra for PNPs and

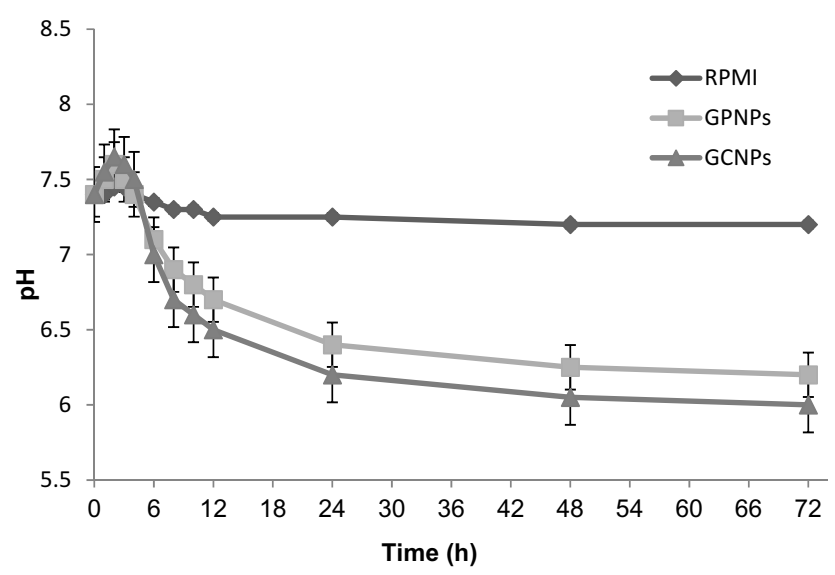

Figure $2 \mathrm{pH}$ variations of treated cells culture media with GCNPs, GPNPs, RPMI as the negative control during MTT assay.

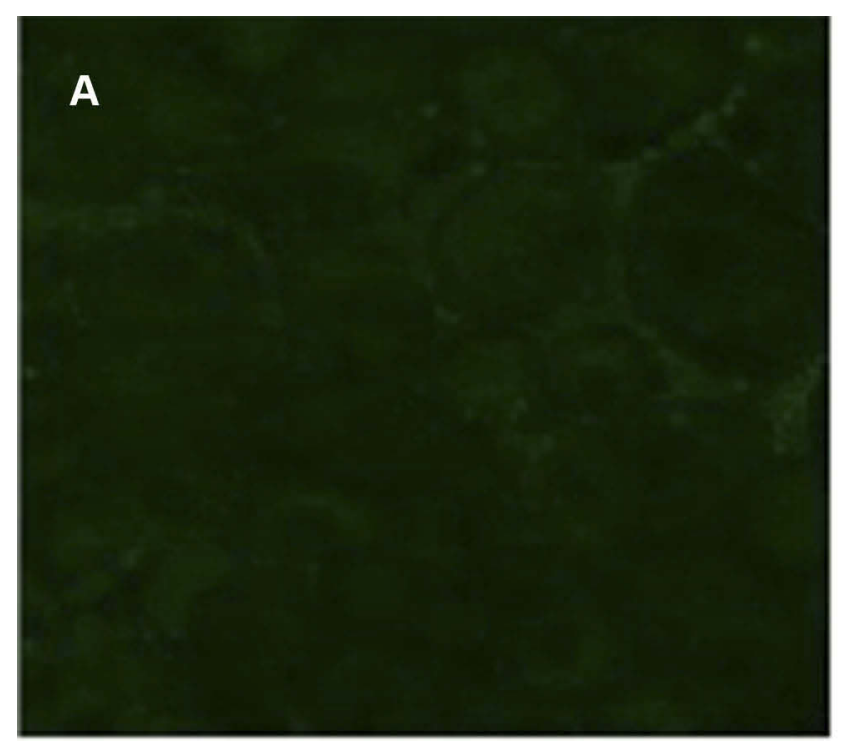

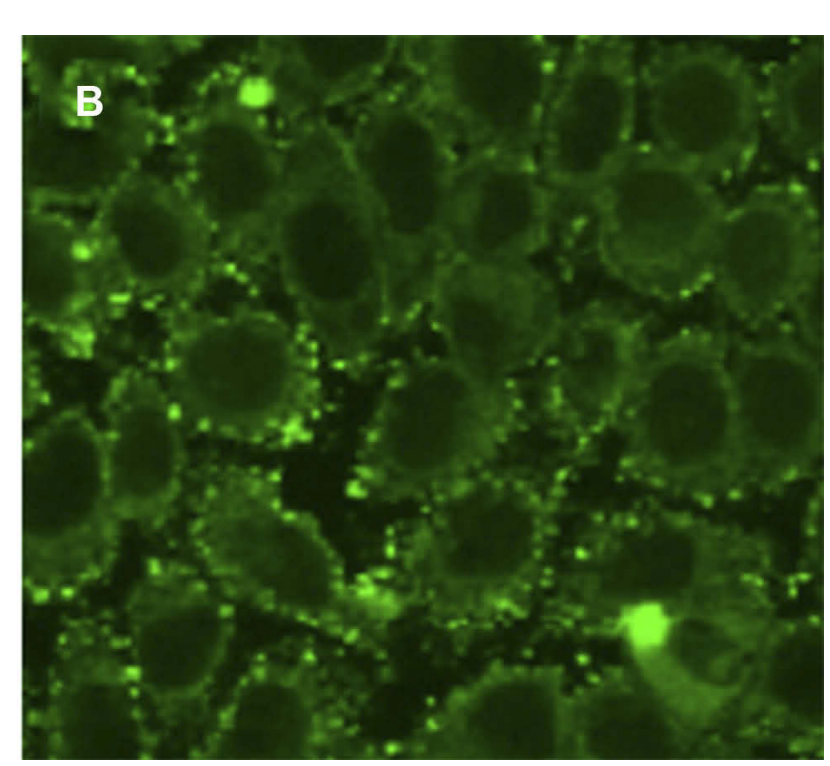

FITC-PNPs have been shown in Figure 8s supplementary materials in more detail. The successful coupling of FITC with PNPs and GPNPs makes it possible to study the interactions of glucose nanoparticles complex with tumor cells visually. To this end, the cellular uptake of PNPs and GPNPs was assayed by fluorescence microscopy. Results indicated that for the cells incubated with FITC-GPNPs, strong fluorescence intensities were observed (Figure 3B), while weak intensities were found in the cells incubated with FITC-PNPs (Figure 3A). This observation verified the FITC-GPNPs interactions with HT-29 cells through the specific affinity between the glucose of the complexes and the Gluts over-expressed in the tumor cell membranes. In fact, the coupling of glucose into PNPs remarkably enhanced the cellular uptake of GPNPs. These interactions can be considered as the main cause of the observed cytotoxicity of GPNPs towards the tumor cells. The proposed mechanism was studied in the following sections in more detail.

\section{GPNPs Induced Apoptosis in HT-29 Cells}

The potential of GPNPs treatment to enforce apoptosis in HT-29 cells was examined by an Annexin V-FITC test to appoint the relation between anti-proliferation and apoptosis. Apoptotic and necrotic cells were identified based on a double-labeling for Annexin V-FITC and PI, a membraneimpermeable DNA stain. The percentage changes in the viable cells, necrotic cells, and early and late apoptosis HT29 cells were determined in four treatments (i.e., 1-RPMI (control), 2-PNPs, 3-GPNPs, and 4-cisplatin at their $\mathrm{IC}_{50}$

Figure 3 Cellular uptake of (A) FITC-PNPs and (B) FITC-GPNPs after 24 h. 
concentrations) after $72 \mathrm{~h}$. The obtained results have been shown in Figure 4. It was revealed that GPNPs treatment of HT-29 cells resulted in the highest percentage of apoptosis among the studied treatments. In the same way, both early and late HT-29 cells apoptotic death rates treated with GPNPs were considerably higher than the control samples $(\mathrm{P}<0.05)$. The percentage of viable cells reduced to $47 \%$ after $72 \mathrm{~h}$ of treatment with GPNPs while there were a meager number of necrotic, early and late apoptotic cells in the control test samples. The percentage of early apoptotic cells significantly $(\mathrm{P}<0.05)$ enhanced from RPMI and PNPs to GPNPs and cisplatin treatments, which was measured equal to $3.0 \%, 4.2 \%, 19.7 \%$, and $23.1 \%$ for RPMI, PNPs, GPNPs, and cisplatin, respectively. The distribution of the late apoptotic cell was $0.7 \%$ for RPMI samples. The late apoptotic cells percentage also improved significantly $(\mathrm{P}<0.05)$ to $1.90 \%, 30.78 \%$, and $21.30 \%$ for PNPs, GPNPs, and cisplatin treatments, respectively. However, the applied treatments with GPNPs and cisplatin slightly affected the percentage of the necrotic cells in the distribution of the cells. In the control sample, the necrotic cells were $0.45 \%$, while in the PNPs, GPNPs, and cisplatin-treated cells, this value increased to $1.60 \%, 2.09 \%$, and $3.10 \%$, respectively. Therefore, the GPNPs treated cells overall population showed a significant increase in apoptosis $(\mathrm{P}<0.05)$ which was even higher than the cisplatin results.

\section{Expression Changes of GLUT-I and GLUT-4 mRNAs in HT-29 Cells}

GLUT-1 and GLUT-4 proteins, among the glucose transporters, have an essential role in the adjustment of transportation of glucose in HT-29 cells. $^{8,33}$ Therefore, the

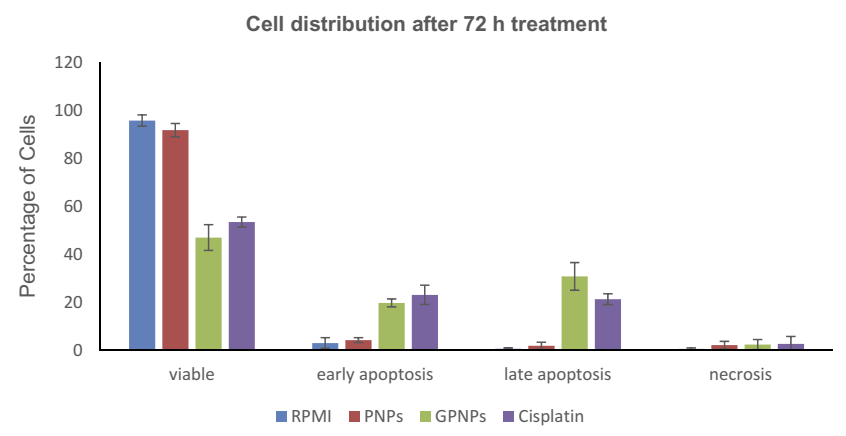

Figure 4 Analysis of apoptosis by the Annexin V-FITC binding assay. HT-29 cells were treated with (I) RPMI (control), (2) PNPs, (3) GPNPs and (4) cisplatin at IC 50 concentrations of $72 \mathrm{~h}(2.54 \mu \mathrm{M}$ for cisplatin and $85.01 \mu \mathrm{M}$ for GPNPs and PNPs) for $72 \mathrm{~h}$. Percentage of cells in viable, early apoptosis (Annexin +/PI-), late apoptosis (Annexin+/PI+), and necrosis (Annexin-/PI+) are shown after $72 \mathrm{~h}$ of treatment. Reported data are the mean values of three independent experiments performed in triplicate. expression pattern of these proteins in HT-29 cells before and after treatment with PNPs and GPNPs was analyzed using RT-PCR. The obtained results are helpful in understanding the molecular mechanism by which GPNPs cause apoptosis induction.

The HT-29 cells were treated with the positive control (cisplatin), negative control (RPMI), PNPs and GPNPs (at $\mathrm{IC}_{50}$ concentrations) at $37^{\circ} \mathrm{C}$ after $24 \mathrm{~h}$ and $72 \mathrm{~h}$ in a humidified incubator with $5 \% \mathrm{CO}_{2}$. Then, the mRNA abundances of GLUT-1 and GLUT-4 assayed by RT-PCR and the obtained data were normalized to the respective vehicle controls. The results have been shown in Figure 5. As can be seen, GPNPs treatment significantly upregulated the GLUT-1 mRNA abundance by $145 \%$ after $24 \mathrm{~h}(\mathrm{P}<0.05)$, while the treatment by PNPs had little effect on the GLUT-1 expression in comparison with the negative control. In contrast, GPNPs treatment after $72 \mathrm{~h}$ reduced the GLUT-1 mRNA abundance to $44 \%$ of the negative control $(\mathrm{P}<0.05)$. Remarkably, there were no significant effects on the GLUT-4 mRNAs expression after 24 and $72 \mathrm{~h}$ treatment with GPNPs. The same trends were observed for the positive control which supported the obtained results for GPNPs treatment. In fact, HT-29 cells significantly upregulate the GLUT-1 mRNA expression in response to the interactions of the GPNPs with GLUT-1 in the early treatment times (24 h). It seems that blocking of the entries of nutrients and reduction of the intracellular glucose level as a result of such interactions trigger the observed higher expression of the GLUT-1 mRNA. In other words, the GLUT-1 overexpression is a possible mechanism to facilitate the entrance of the nutrients to HT-29 cells as a remedy for the decrease of the intracellular glucose level. After $72 \mathrm{~h}$, the GLUT-1 mRNAs expression was reduced to $44 \%$ in the cells. It was shown in the previous section that the apoptosis percentage increased at this time. In fact, the gene expression premiership started to upregulate the expression of apoptotic enzymes and downregulate the GLUT-1 expression.

\section{Discussion}

Results of the stability analysis for the synthesized glucose nanoparticle complexes showed that lower temperatures and higher $\mathrm{pH}$ values in the range of study were more favorable. Higher temperatures can facilitate the complex decomposition, which in turn reduces the stability. The formation of polyanions in acidic conditions causing the network hardening in the structure of nanoparticles, which in turn reduces the swelling of the polymer as well as the nanoparticles surface area, has been known to be the main 

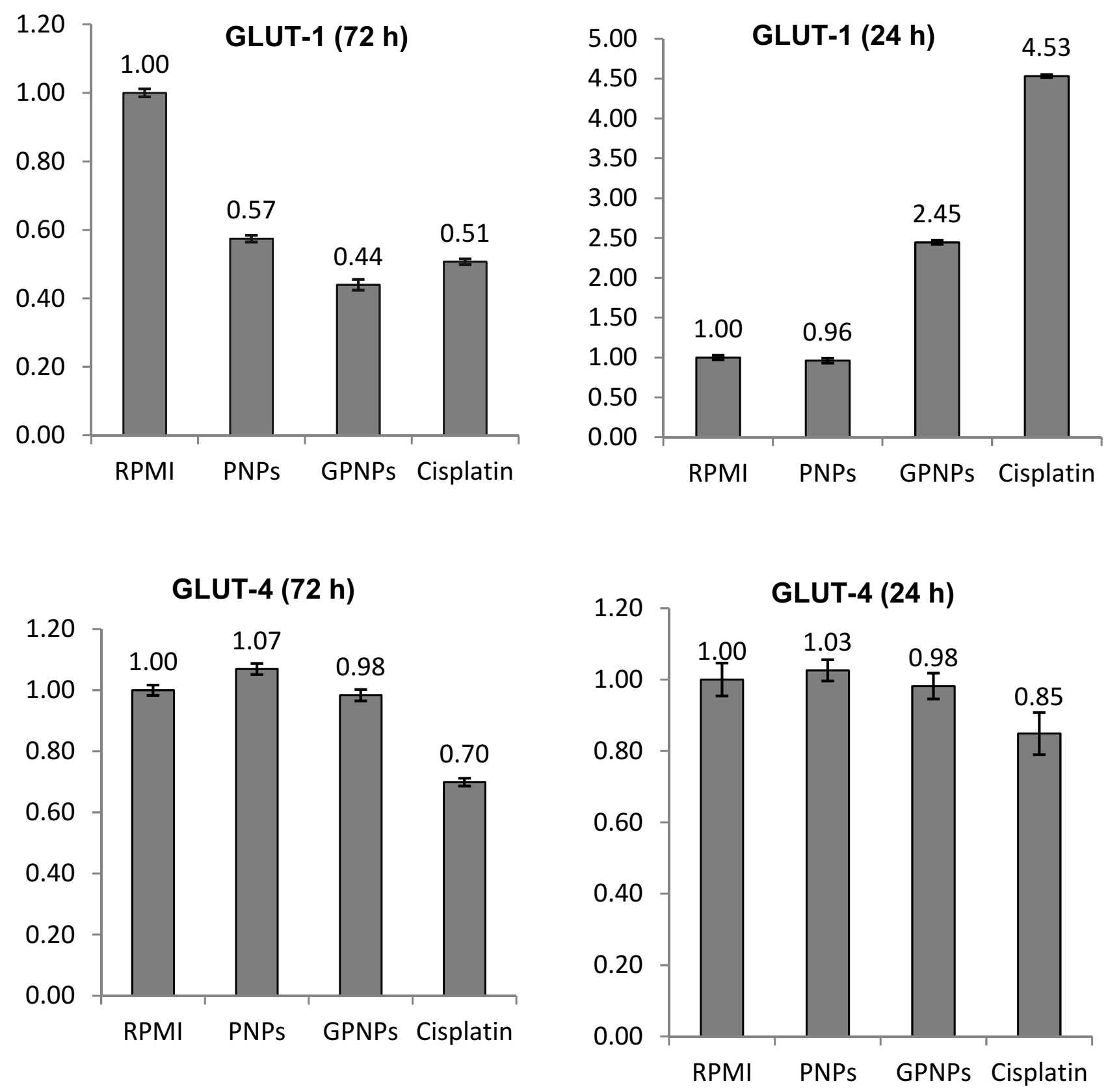

Figure 5 Effects of GPNPs treatment at 24 and $72 \mathrm{~h}$ on the expressions of GLUT-I and GLUT-4 proteins in the HT-29 cell line.

reason for the more stability observed in the lower $\mathrm{pH}$ values. ${ }^{34-36}$ Kuchak $^{37}$ have reported the same stability trend for diclofenac-loaded CNPs in acidic conditions and interpreted their results by the same network tightening of nanoparticle systems. In fact, the more stability of our complexes in the lower $\mathrm{pH}$ values is desirable in this work because the microenvironment of the cancerous tissues can have lower $\mathrm{pH}$ values as a result of the fermentative metabolism of glucose by the tumor cells. Generally, the obtained stability for the studied complexes was at least $80 \%$ after 24 days, which was appropriate for the considered application.

The cytotoxicity evaluation of the glucose nanoparticle complexes resulted in $57 \%$ and $54 \%$ reduction $(\mathrm{P}<0.05)$ in the HT-29 cells survival after $72 \mathrm{~h}$ of incubation for GCNPs and GPNPs, respectively. It supposed that the exposure of glucose nanoparticle complexes to the Gluts of the tumor cells would result in binding the glucose moiety of the complexes with the overexpressed Gluts on the cancer cell membranes. This assumption was verified 
by fluorescence microscopy of the treated cells with FITCGPNPs and comparing the fluorescence intensity of the obtained images with those of the FITC-PNPs treatment. Consequently, the observed anti-cancer effect of the examined glucose nanoparticle complexes can be explained by the permanent occupation of the active sites of the cancer cell Gluts by the glucose nanoparticle complexes. At first, the glucose moiety will bind an active Glut site on the cell membrane. Considering the terminal binding of the glucose molecule to the nanoparticle, it cannot be imported into the cell because of the nanoparticle shape, size, and affinity. Consequently, the formed glucose-Glut bonds start to occupy the Glut transporters all over the cell membrane while the cells cannot get rid of these complexes, which ultimately cause the inactivation of the majority of the Glut transporters and blocking the entries of nutrients to the cells. The final result will be the inaccessibility of nutrients, lack of the required energy for cellular activity, and death of the cancer cells. The Gluts have been centered as an important target in the anti-cancer therapeutics development in recent years because of the significance of the irregular glucose metabolism in the cancer cells known as the Warburg effect. ${ }^{8}$ Many efforts have been devoted to find out effective chemical inhibitors to Gluts or suppress their expression by methods to modify the cell metabolism. ${ }^{38,39}$ Many Glut inhibitors have been reported in the literature, including both the natural compounds such as Resveratrol ${ }^{38}$ and synthetic compounds like polyphenolic esters, ${ }^{40}$ which have been reviewed by Granchi. ${ }^{39}$ Besides, the positive effect of the conjugation of anticancer drugs with sugars that facilitate their uptake by the cells has been mentioned. ${ }^{39}$ However, the utilization of glucose decorated nanoparticles to hinder the cell glucose uptake has not been reported before.

It was observed that the $\mathrm{pH}$ value of the medium decrease after treatment of the HT-29 cells with glucose decorated nanoparticles, and the rate of reduction was higher at the early times of treatment (first $24 \mathrm{~h}$ ). This observation can be justified by the depletion of glucose concentration in the cells and the excretion of more lactate during this time. In fact, it is well known that the promoter sequence of lactate dehydrogenase upregulates in the glucose deprivation conditions and involves both the HRE and c-Myc binding sites. The activation of the c-Myc results in the activation of transcription of glucose transporters and glycolytic enzymes. ${ }^{41}$ The obtained RT-PCR results in this work indicated that the expression of Glut1 increased in the first $24 \mathrm{hrs}$, which was in agreement with the hypoxic regulation of glucose transport in the cancer cells and the observed $\mathrm{pH}$ reduction in the samples.

Aggressive and uncontrolled proliferation is the main characteristic of cancer cells, which increases their constant energy request. Tumors miss a blood supply because of inadequate vascularization, which makes oxygen deficiency. Tumor cells, under this hypoxic condition, express hypoxia-inducible factor (HIF), their GLUT-1 downstream gene adapts to this microenvironment, ${ }^{42,43}$ and to compensate for the energy shortage, anaerobic glycolysis enhances. Therefore, glucose transporters (such as GLUT-1 and GLUT-4) have a definitive role in the metabolism of tumor cells, and the repression of their activity could efficiently control the growth of cancer cells and cause apoptosis induction of the cancer cells. Our RT-PCR results showed that the expression of Glut1 in HT-29 cells was considerably reduced after $72 \mathrm{~h}$ of treatment with GPNPs, which coincided with the substantial increase in the apoptotic percentage of the cells. These observations confirmed the great potential of the synthesized GPNPs in the cancer therapeutic applications.

\section{Conclusions}

GPNP and GCNP complexes have been synthesized to investigate their interactions with Gluts overexpressed in HT-29 cancer cells. Their stability was confirmed in various $\mathrm{pH}$ and temperature conditions. The glucose conjugated nanoparticle complexes showed anti-proliferative activity on HT-29 cells at high concentrations after $72 \mathrm{~h}$ in the absence of any anticancer drug loading. These complexes showed a significant cellular uptake through fluorescence microscopy of FITCGPNPs because of the strong affinity of the glucose moiety of the complex with the Gluts of the cancer cells. Moreover, flow cytometry results revealed proapoptotic effects on HT29 cells after treatment by GPNPs. It was disclosed that the expression of GLUT-1 mRNA after the first $24 \mathrm{~h}$ of treatment by GPNPs was upregulated, while the direction has been reversed after $72 \mathrm{~h}$ incubation, which coincided with the death of the cells. In fact, glucose decorated nanoparticles blocked the Gluts on the tumor cells membranes effectively, leading to the end of the cells. This makes GPNPs promising drug systems for the treatment of cancer by targeting the Gluts.

\section{Abbreviations}

4T1, Breast cancer cell line derived from the mammary gland tissue of a mouse BALB/c; Annexin V-FITC, Annexin V-fluorescein isothiocyanate; BBB, blood-brain barrier; 
$\mathrm{CDCl}_{3}$, chloroform; CNPs, chitosan nanoparticles; DCM, dichloromethane; DLS, dynamic light scattering; DMAP, 4-dimethylamino pyridine; DMSO, dimethyl sulfoxide; DS, degree of substitution; EDC, 1-ethyl-3-(3dimethylaminopropyl) carbodiimide; ELISA, enzyme-linked immunosorbent assay; EMA, European Medical Agency; EPR, enhanced permeability and retention; FBS, fetal bovine serum; FDA, food and drug administration; FITC, fluorescein isothiocyanate; FTIR, fourier-transform infrared spectroscopy; GCNPs, glucose chitosan nanoparticles; Gluts, glucose transporters; GPNPs, glucose-PLGA nanoparticles; HEPES, 4-(2-hydroxyethyl)-1-piperazineethanesulfonic acid; HIF, hypoxiainducible factor; HRE, hypoxia response element; HT-29, human colon tumor cells; $\mathrm{IC}_{50}$, concentration of drugs required for $50 \%$ cell growth inhibition; MCF-7, human caucasian/breast cancer cells; MES, 2-(n-morpholino)ethanesulfonic acid; MaxV, maximum viability; MinV, minimal viability; mRNA, messenger ribonucleic acid; MTT, 3-(4,5-dimethylthiazol-2-yl)-2,5- diphenyl tetrazolium bromide; c-Myc, cellular-Myelocytomatosis; NHS, N-hyd roxysuccinimide; NMR, nuclear magnetic resonance; PBS, phosphate buffered saline; PDI, polydispersity index; PI, propidium iodide; PLGA, Poly(lactic-co-glycolic acid); PNPs, PLGA nanoparticles; RH, relative humidity; RNA, ribonucleic acid; RT-PCR, real-time polymerase chain reaction; RPMI 1640, Roswell Park Memorial Institute medium; SEM, scanning electron microscopy; TPP, sodium tripolyphosphate.

\section{Disclosure}

The authors report no conflicts of interest in this work.

\section{References}

1. Bahrami B, Hojjat-Farsangi M, Mohammadi H, et al. Nanoparticles and targeted drug delivery in cancer therapy. Immunol Lett. 2017;190:64-83. doi:10.1016/j.imlet.2017.07.015

2. Ge Y, Ma Y, Li L. The application of prodrug-based nano-drug delivery strategy in cancer combination therapy. Colloids Surf B Biointerfaces. 2016;146:482-489. doi:10.1016/j.colsurfb.2016.06.051

3. Mokhtarzadeh A, Hassanpour S, Vahid ZF, et al. Nano-delivery system targeting to cancer stem cell cluster of differentiation biomarkers. J Control Release. 2017;266:166-186. doi:10.1016/j.jconrel.2017. 09.028

4. Raavé R, van Kuppevelt TH, Daamen WF. Chemotherapeutic drug delivery by tumoral extracellular matrix targeting. J Control Release. 2018;274:1-8. doi:10.1016/j.jconrel.2018.01.029

5. Thanuja MY, Anupama C, Ranganath SH. Bioengineered cellular and cell membrane-derived vehicles for actively targeted drug delivery: so near and yet so far. Adv Drug Deliv Rev. 2018;132:57-80

6. Parks SK, Cormerais Y, Marchiq I, Pouyssegur J. Hypoxia optimises tumour growth by controlling nutrient import and acidic metabolite export. Mol Aspects Med. 2016;47-48:3-14. doi:10.1016/j.mam. 2015.12.001
7. Warburg O, Wind F, Negelein E. The metabolism of tumors in the body. J Gen Physiol. 1927;8(6):519-530. doi:10.1085/jgp.8.6.519

8. Barron CC, Bilan PJ, Tsakiridis T, Tsiani E. Facilitative glucose transporters: implications for cancer detection, prognosis and treatment. Metabolism. 2016;65(2):124-139. doi:10.1016/j.metabol. 2015.10.007

9. Montiel Schneider MG, Martin MJ, Coral DF, et al. Selective contrast agents with potential to the earlier detection of tumors: insights on synthetic pathways, physicochemical properties and performance in MRI assays. Colloids Surf B Biointerfaces. 2018;170:470-478. doi:10.1016/j.colsurfb.2018.06.044

10. Liu D-Z, Sinchaikul S, Reddy PVG, Chang M-Y, Chen S-T. Synthesis of 2'-paclitaxel methyl 2-glucopyranosyl succinate for specific targeted delivery to cancer cells. Bioorg Med Chem Lett. 2007;17(3):617-620. doi:10.1016/j.bmcl.2006.11.008

11. Wu M, Li H, Liu R, et al. Galactose conjugated platinum(II) complex targeting the Warburg effect for treatment of non-small cell lung cancer and colon cancer. Eur J Med Chem. 2016;110:32-42. doi:10.1016/j.ejmech.2016.01.016

12. Gao X, Liu S, Shi Y, et al. Mechanistic and biological characteristics of different sugar conjugated 2-methyl malonatoplatinum(II) complexes as new tumor targeting agents. Eur J Med Chem. 2017;125:372-384. doi:10.1016/j.ejmech.2016.09.047

13. Jiang X, Xin H, Ren Q, et al. Nanoparticles of 2-deoxy-d-glucose functionalized poly(ethylene glycol)-co-poly(trimethylene carbonate) for dual-targeted drug delivery in glioma treatment. Biomaterials. 2014;35(1):518-529. doi:10.1016/j.biomaterials.2013.09.094

14. Asik E, Aslan TN, Volkan M, Guray NT. 2-Amino-2-deoxy-glucose conjugated cobalt ferrite magnetic nanoparticle (2DG-MNP) as a targeting agent for breast cancer cells. Environ Toxicol Pharmacol. 2016;41:272-278. doi:10.1016/j.etap.2015.12.004

15. Li J, Ma F-K, Dang Q-F, Liang X-G, Chen X-G. Glucose-conjugated chitosan nanoparticles for targeted drug delivery and their specific interaction with tumor cells. Front Mater Sci. 2014;8(4):363-372. doi:10.1007/s11706-014-0262-8

16. Vunain E, Mishra AK, Mamba BB. 1 - Fundamentals of chitosan for biomedical applications. In: Jennings JA, Bumgardner JD, editors. Chitosan Based Biomaterials. Vol. 1. Woodhead Publishing; 2017:3-30.

17. Choi C, Nam J-P, Nah J-W. Application of chitosan and chitosan derivatives as biomaterials. J Ind Eng Chem. 2016;33:1-10. doi:10.1016/j.jiec.2015.10.028

18. Vyas R, Gupta N, Nimesh S. Chapter 9 - Chitosan nanoparticles for efficient and targeted delivery of anticancer drugs. In: Grumezescu AM, editor. Nanobiomaterials in Cancer Therapy. William Andrew Publishing; 2016:281-306.

19. Fonseca-Santos B, Chorilli M. An overview of carboxymethyl derivatives of chitosan: their use as biomaterials and drug delivery systems. Mater Sci Eng C. 2017;77:1349-1362. doi:10.1016/j. msec.2017.03.198

20. Mir M, Ahmed N, Rehman A. Recent applications of PLGA based nanostructures in drug delivery. Colloids Surf B Biointerfaces. 2017;159:217-231. doi:10.1016/j.colsurfb.2017.07.038

21. Son J, Yang SM, Yi G, et al. Folate-modified PLGA nanoparticles for tumor-targeted delivery of pheophorbide a in vivo. Biochem Biophys Res Commun. 2018;498(3):523-528. doi:10.1016/j.bbrc.2018.03.013

22. Calvo P, Remuñán-López C, Vila-Jato JL, Alonso MJ. Novel hydrophilic chitosan-polyethylene oxide nanoparticles as protein carriers. J Appl Poly Sci. 1997;63(1):125-132. doi:10.1002/(SICI)1097-4628(19970103)63:1<125::AID-APP13>3.0.CO;2-4

23. Xiguang Chen JL, Cheng X, Inventor TJ. Process for preparing compounds of chitosan saccharified with aminosugar. 2008.

24. Pereira C, Costa J, Sarmento B, Araújo F. 3.3 - Cell-based in vitro models for intestinal permeability studies. In: Sarmento B, editor. Concepts and Models for Drug Permeability Studies. Woodhead Publishing; 2016:57-81. 
25. Adlin Jino J. Nesalin AAS. Preparation and evaluation of chitosan nanoparticles containing zidovudine. Asian J Pharm Sci. 2012;7 (1):80-84.

26. Abolhasani H, Zarghi A, Abolhasani A, et al. Design, synthesis and in vitro cytotoxicity evaluation of new 3',4'-bis (3,4,5-trisubstituted)4'H-spiro[indene-2,5'-isoxazol]-1(3H)-one derivatives as promising anticancer agents. Lett Drug Des Discov. 2014;11(10):1149-1161. doi:10.2174/1570180811666140704172442

27. Abolhasani A, Heidari F, Noori S, Mousavi S, Abolhasani H. Cytotoxicity evaluation of dimethoxy and trimethoxy indanonic spiroisoxazolines against cancerous liver cells. Curr Chem Biol. 2019;13(3).

28. Wang X, Yang L, Zhang H, et al. Fluorescent magnetic PEI-PLGA nanoparticles loaded with paclitaxel for concurrent cell imaging, enhanced apoptosis and autophagy in human brain cancer. Colloids Surf B Biointerfaces. 2018;172:708-717. doi:10.1016/j.colsurfb.2018.09.033

29. Rescignano N, Tarpani L, Romani A, et al. In-vitro degradation of PLGA nanoparticles in aqueous medium and in stem cell cultures by monitoring the cargo fluorescence spectrum. Polym Degrad Stab. 2016;134:296-304. doi:10.1016/j.polymdegradstab.2016.10.017

30. Sena P, Mancini S, Benincasa M, Mariani F, Palumbo C, Roncucci L. Metformin induces apoptosis and alters cellular responses to oxidative stress in Ht29 colon cancer cells: preliminary findings. Int J Mol Sci. 2018;19:5. doi:10.3390/ijms19051478

31. Alarifi S, Ali H, Alkahtani S, Alessia MS. Regulation of apoptosis through bcl-2/bax proteins expression and DNA damage by nano-sized gadolinium oxide. Int J Nanomedicine. 2017;12:4541-4551. doi:10.2147/ IJN.S139326

32. Montel-Hagen A, Blanc L, Boyer-Clavel M, et al. The Glut1 and Glut4 glucose transporters are differentially expressed during perinatal and postnatal erythropoiesis. Blood. 2008;112(12):4729. doi:10.1182/blood-2008-05-159269

33. Calvo MB, Figueroa A, Pulido EG, Campelo RG, Aparicio LA. Potential role of sugar transporters in cancer and their relationship with anticancer therapy. Int J Endocrinol. 2010;2010:14. doi:10.1155/ $2010 / 205357$
34. Swider E, Staal AHJ, Koen van Riessen N, et al. Design of triphasic poly (lactic-co-glycolic acid) nanoparticles containing a perfluorocarbon phase for biomedical applications. RSC Adv. 2018;8(12):6460-6470. doi:10.1039/C7RA13062G

35. Wan S, Zhang L, Quan Y, Wei K. Resveratrol-loaded PLGA nanoparticles: enhanced stability, solubility and bioactivity of resveratrol for non-alcoholic fatty liver disease therapy. $R$ Soc Open Sci. 2018;5:181457. doi:10.1098/rsos.181457

36. Barbosa AI, Costa Lima SA, Reis S. Application of pH-responsive fucoidan/chitosan nanoparticles to improve oral quercetin delivery. Molecules. 2019;24(2):346. doi:10.3390/molecules24020346

37. Maryam K, Azarpanah A. Preparation and in vitro evaluation of chitosan nanoparticles containing diclofenac using the ion-gelation method. Jundishapur J Nat Pharm Prod. 2015;10:1-7.

38. Zambrano A, Molt M, Uribe E, Salas M. Glut 1 in cancer cells and the inhibitory action of resveratrol as a potential therapeutic strategy. Int J Mol Sci. 2019;20(13):3374. doi:10.3390/ijms20133374

39. Granchi C, Fortunato S, Minutolo F. Anticancer agents interacting with membrane glucose transporters. MedChemComm. 2016;7 (9):1716-1729. doi:10.1039/C6MD00287K

40. Zhang W, Liu Y, Chen X, Bergmeier SC. Novel inhibitors of basal glucose transport as potential anticancer agents. Bioorg Med Chem Lett. 2010;20(7):2191-2194. doi:10.1016/j.bmcl.2010.02.027

41. Airley RE, Mobasheri A. Hypoxic regulation of glucose transport, anaerobic metabolism and angiogenesis in cancer: novel pathways and targets for anticancer therapeutics. Chemotherapy. 2007;53 (4):233-256. doi:10.1159/000104457

42. Choudhry H, Harris AL. Advances in hypoxia-inducible factor biology. Cell Metab. 2018;27(2):281-298. doi:10.1016/j.cmet.2017. 10.005

43. Lv X, Li J, Zhang C, et al. The role of hypoxia-inducible factors in tumor angiogenesis and cell metabolism. Genes Dis. 2017;4 (1):19-24. doi:10.1016/j.gendis.2016.11.003
International Journal of Nanomedicine

\section{Publish your work in this journal}

The International Journal of Nanomedicine is an international, peerreviewed journal focusing on the application of nanotechnology in diagnostics, therapeutics, and drug delivery systems throughout the biomedical field. This journal is indexed on PubMed Central, MedLine, CAS, SciSearch ${ }^{\circledR}$, Current Contents ${ }^{\mathbb{R}} /$ Clinical Medicine, $^{-}$
Journal Citation Reports/Science Edition, EMBase, Scopus and the Elsevier Bibliographic databases. The manuscript management system is completely online and includes a very quick and fair peer-review system, which is all easy to use. Visit http://www.dovepress.com/ testimonials.php to read real quotes from published authors 